GRASAS Y ACEITES 65 (4)

October-December 2014, e052

ISSN-L: 0017-3495

doi: http://dx.doi.org/10.3989/gya.0231141

\title{
The use of artificial neural network modeling to represent the process of concentration by molecular distillation of omega- 3 from squid oil
}

\author{
P. Rossi ${ }^{\mathrm{a},}$, M.F. Gayol ${ }^{\mathrm{a}}$, C. Renaudo ${ }^{\mathrm{a}}$, M.C. Pramparo ${ }^{\mathrm{a}}$, V. Nepote ${ }^{\mathrm{b}}$ and N.R. Grosso \\ ${ }^{a}$ Facultad de Ingeniería, Universidad Nacional de Río Cuarto, Río Cuarto, Córdoba, Argentina \\ ${ }^{b}$ ICTA, Facultad de Ciencias Exactas, Físicas y Naturales (UNC), IMBIV-CONICET, Córdoba, Argentina \\ 'Química Biológica, Facultad de Ciencias Agropecuarias (UNC), IMBIV-CONICET, Córdoba, Argentina \\ ${ }^{\circledR}$ Corresponding author: prossi@ing.unrc.edu.ar
}

Submitted: 20 February 2014; Accepted: 03 August 2014

\begin{abstract}
SUMMARY: The concentration of omega-3 compounds obtained for the esterification of squid oil by molecular distillation was carried out in two stages. This operation can process these thermolabile and high molecular weight components at very low temperatures. Given the mathematical complexity of the theoretical model, artificial neural networks (ANN) have provided an alternative to a classical computing analysis. The objective of this study was to create a predictive model using artificial neural network techniques to represent the concentration process of omega-3 compounds obtained from squid oil using molecular distillation. Another objective of this study was to analyze the performance of two different alternatives of ANN modeling; one of them is a model that represents all variables in the process and the other is a global model that simulates only the input and output variables of the process. The alternative of the ANN global model showed the best fit to the experimental data.
\end{abstract}

KEYWORDS: Artificial Neural Networks; DHA; EPA; Molecular Distillation; Omega-3

RESUMEN: Uso de modelos de redes neuronales artificiales para representar el proceso de concentración por destilación molecular de omega-3 proveniente de aceite de calamar. La concentración de compuestos omega-3, obtenidos de la esterificación de aceite de calamar, por destilación molecular fue llevada a cabo en dos etapas. Esta operación permite procesar componentes termolábiles y de alto peso molecular a muy bajas temperaturas. Dada la alta complejidad de los modelos teóricos, las redes neuronales artificiales (RNA) conforman una alternativa al análisis computacional clásico. El objetivo de este estudio fue crear un modelo predictivo usando modelos de redes neuronales artificiales para representar el proceso de concentración de compuestos omega-3 obtenidos del aceite de calamar por destilación molecular. Otro objetivo de este estudio fue analizar el desenvolvimiento de dos alternativas de modelos RNA; uno de ellos es un modelo que representa todas las variables en el proceso y otro es un modelo global que simula solo las variables de entrada y de salida del proceso. La alternativa de un modelo RNA global mostró el mejor ajuste de los datos experimentales.

PALABRAS CLAVE: Destilación Molecular; DHA; EPA; Omega-3; Redes Neuronales Artificiales

Citation/Cómo citar este artículo: Rossi P, Gayol MF, Renaudo C, Pramparo MC, Nepote V, Grosso NR. 2014. The use of artificial neural network modeling to represent the process of concentration by molecular distillation of omega-3 from squid oil. Grasas Aceites 65 (4): e052. doi: http://dx.doi.org/10.3989/gya.0231141.

Copyright: (C) 2014 CSIC. This is an open-access article distributed under the terms of the Creative Commons Attribution-Non Commercial (by-nc) Spain 3.0 Licence. 


\section{INTRODUCTION}

Molecular distillation is based on the evaporation of components from a mixture, usually in the form of a falling film, produced by contact with a heated surface, followed by subsequent condensation on a cold surface. Thus, molecular distillation or short-path distillation is a special type of ultra-high vacuum distillation that takes place in special equipment where the distance between the evaporation and condensation surfaces is shorter than its mean free path. This technology is useful for the separation, purification and concentration of thermo labile substances with low vapor pressure (Pramparo et al., 2008).

The main feature of this operation is the operative pressure (10-0.1 Pa). Under these conditions, the relative volatility of components increases and temperature decreases, allowing for the separation of compounds at lower temperatures. The molecules that leave the evaporation surface suffer no collisions before their condensation (Setyawan et al., 2011). Unlike conventional distillation where the equilibrium of evaporation-condensation is established, molecular distillation where the molecules that leave the evaporation surface travel a short distance before their condensation so they access the condenser surface without delay. Because of this molecular distillation condition, the evaporation rates are very high, reducing the residence time of molecules during the process. Under these two conditions, a short residence time and low temperature, the thermal decomposition of the components does not take place and separation occurs at technologically acceptable rates (Setyawan et al., 2011; Posada et al., 2007).

The degree of separation that is achieved by a molecular distillation process is not an exclusive function of the relative volatilities of the compounds, since transport resistances and the interfacial resistance characteristic of the molecular kinetic play an important role in the performance of this operation. When the liquid evaporates, the vapor-liquid interface is cooled and, for mixtures, the composition of the most volatile components decreases in the interface. This leads to the formation of driving forces for mass, diffusive, and heat transfers (Vansant, 1994).

The detailed mathematical description of the phenomena that occur in this operation generates a complex mathematical resolution, resulting in numerous studies aimed at finding the best model for this process. With regard to the mathematical description of molecular distillation with phenomenological models, many advances have been reported, ranging from the modeling of a conventional falling film evaporator to specific molecular distillators derived from the first ones. Lutisan et al. (2002) showed that the existence of concentration and temperature gradients in the liquid phase decreases the separation efficiency. Ferron and Bandarkar (1991) worked on mass and heat transfer in a liquid film on a centrifugal conical evaporator. Tovars et al. (2012) provided comparative results of efficiency and performance between falling film molecular distillation and centrifugal molecular distillation equipment. In addition, advances in the non-ideality of the vapor phase were published by $\mathrm{Hu}$ et al. (2013). The effect of pressure on the molecular distillation process has been analyzed by $\mathrm{Hu}$ et al. (2013) using the Boltzmann distribution and the Maxwell function for the velocity of molecules in the vapor phase.

Given the mathematical complexity of the phenomenological model that this operation represents, new solution techniques have been studied, including Artificial Neural Networks (ANN) (Bulsari, 1995). An ANN is a set of simple elements that are interconnected and use these connections to send information through the network. The network is primarily composed of 1) processing elements or neurons, 2) inputs to neurons, 3 ) weights of connections, 4) activation functions, and 5) transfer output functions. The processing elements of the ANN are distributed in layers: an input layer which receives the input variables; hidden layers where neurons have no contact with external elements, and an output layer which receives the information processed in the previous layers and also provides the answers for which it was trained (Haykin, 2009).

Depending on how the elements in the different layers are connected and the direction of sequential information flow among layers, networks are classified as feed-forward networks and recurrent networks. In feed-forward networks, unidirectional signals flow from the input layer to the output layer, i.e. data are sent to neurons from the transfer layer to the next layer, but they do not send data to neurons in the same layer. In recurrent networks, the signal moves in two directions and the output of some neurons is forwarded to another neuron or neurons that belong to previous layers (Shao et al., 2007).

ANN have provided an alternative to classical computing for those problems where traditional methods have not provided convincing results, or solutions for complex problems where all phenomena taking place cannot be incorporated into a mathematical model. ANN may have different applications from image and voice processing, pattern recognition, and planning and adaptive interfaces for human/machine systems to signal filtering, prediction, control, and optimization of phenomena. Shao et al. (2007) obtained promising results in optimizing the operation of molecular distillation for recovering tocopherols from the deodorized distillate of rapeseed oil through the artificial neural network modeling. 
Fish oils are a rich source of polyunsaturated fatty acids called omega-3. These kinds of fatty acids have an essential role in the human diet since they have the ability to prevent diseases such as cardiovascular, cancer, Alzheimer, and arthritis. Particularly in fish oils, there are two omega-3 fatty acids, 5,8,11,14,17-eicosapentaenoic acid (EPA, 20:5 03 ) and 4,7,10,13,16,19-docosahexaenoic acid (DHA, 22:6 103 ) that are functional constituents of importance for the physiology of the human body (Swanson, 2012).

Rossi et al. (2011) optimized the separation process of omega-3 fatty acid ethyl esters obtained from calamari oils using molecular distillation. The separation process was conducted in two stages where operation temperatures ranged from 100 to $120{ }^{\circ} \mathrm{C}$ in the first stage and from 120 to $140{ }^{\circ} \mathrm{C}$ in the second stage. A mathematical model based on the mass transfer phenomena that takes place in isothermal separation of the components was developed. The Langmuir-Knudsen constitutive equation was used to represent evaporation kinetics. The mathematical model was numerically solved and validated by experimental data in the operating region studied.

There is no information available in the literature on modeling of the molecular distillation operation through the artificial neural network to obtain a concentration of omega 3 fatty acids from squid oil. The objective of this study was to create a predictive model using artificial neural network techniques to represent the concentration process by molecular distillation of omega-3 compounds such as the ester ethylics of EPA and DHA obtained from squid oil. Another objective of this study was to analyze the performance of two different alternatives of ANN modeling; one of them is a model that represents all variables in the process and the other is a global model that simulates only input and output variables of the process.

\section{METHODS}

\subsection{Description of the process}

To construct and validate the ANN predictive model experimental data were used from Rossi et al. (2011) along with theoretical concepts based on phenomenological laws.

Squid oil is composed primarily of triglycerides whose fatty acids can be separated by a transesterification reaction with ethyl alcohol whose resulting product is the ethyl ester of the fatty acid (EE). Rossi et al. (2011) reported the EE composition squid Illex argentinus oil analyzed by gas chromatography. In that study, several fatty acids in significant amounts were detected. The chromatography of the feeding sample showed four groups of peaks that mean $70 \%$ of the total total mixture. The four groups are the $22 \%$ group of palmitic acid-EE (PA$\mathrm{EE}$ ), the $18 \%$ group of oleic acid-EE (OA-EE), the $13,3 \%$ group of EPA-EE (EPA-EE), and the $16 \%$ group of DHA-EE (DHA-EE). To simplify the modeling, the fatty acids were grouped into four classes with similar chain lengths. The remaining $30 \%$ is mostly a mixture of organic compounds of high molecular weight. With these compounds, a new group was defined, a group of diglyceride of palmitic and oleic acids which is assumed to have properties similar to the ones of high molecular weight compounds.

Rossi et al. (2011) also reported that the general procedure of the concentration of EPA-EE and DHA-EE by molecular distillation in two consecutive stages. In Stage I, a separation of ethyl esters of the lightest fatty acids occurs, mainly palmitic and oleic acid esters, which exit through the distillate stream. The heaviest components remain as a residue of Stage I and feed the second stage. At this stage, the omega-3 esters, EPA and DHA, evaporate and are recovered in the distillate while heavy residual compounds remain in the residue of Stage II. The operative variables of the distillation process are the evaporation temperatures of Stage I $\mathrm{T}^{1}$ (evaporation temperature of Stage 1) and stage II $\mathrm{T}^{2}$ (evaporation temperature of Stage 2).

\subsection{ANN modeling}

The processing elements of the neural network model used are an input layer, a hidden layer, and an output layer. Interconnections among the different layers can be seen in Figure 1. The number of neurons per layer is chosen according to the numbers of input and output variables and available data.

The development of networks has two stages, the training phase where experimental data are used to make the network imitate the physical phenomenon, and the test phase where real critical values and network approximation values are compared. The training phase occurs due to the learning ability of the ANN. Network learning is a process for fixing the ANN free parameters through a continuous stimulation in the environment where the system is located. For a given ANN topology, it is possible to work with different forms of learning which increase their applications (Haykin, 2009).

In this study, the network used in the simulation of the process was the multilayer perceptron network with the back-propagation supervised learning method (Haykin, 2009). For the practical application of the ANN, the Neural Network toolbox from the software suite MATLAB 8.2 (Mathworks, 2013) was used. This toolbox allows for the modeling of several network topologies with different learning styles. Experimental data and phenomenological concepts were used to construct and to validate the ANN predictive model. 


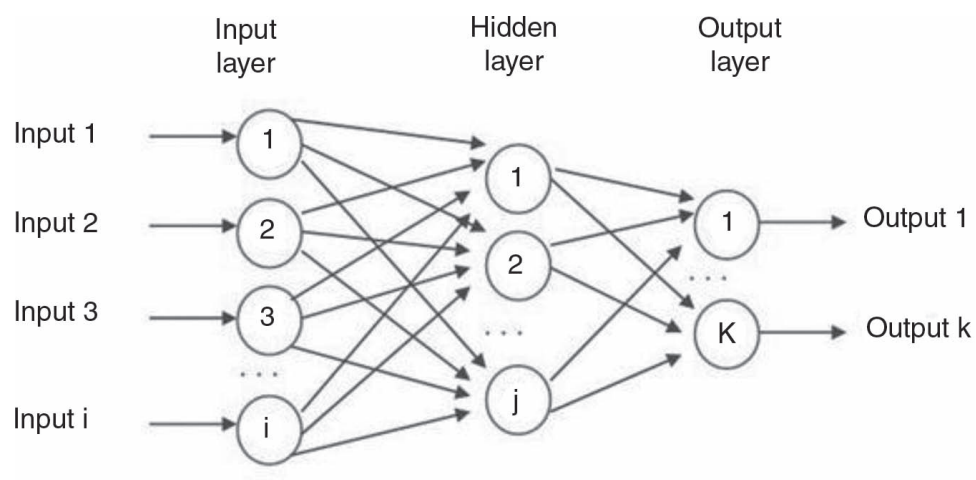

FIGURE 1. Structure of the artificial neural network used in modeling the molecular distillation operation.

Algorithms are used to model ANN. An algorithm consists of an initial loop where the neuron number of the hidden layer is fixed and looks for the best training adjusted to the experimental data. A second loop contains the first loop and includes the variation in neuron number in the hidden layer. Finally, the results of the algorithm are the optimum number of the hidden layer with the corresponding best training. The flow sheet of the algorithm used to model the process of concentration of omega-3 compounds by molecular distillation for obtaining the optimum number of neurons in the hidden layer with its corresponding best training are shown in Figure 2. An algorithm was developed to find the predictive model of the best performance. This algorithm finds the best training to fit to the experimental data. Training was carried out through a series of successive trainings in the feed forward phase. The search for the best training was carried out in two stages: first stage one, which aims the best training for a fixed number of hidden neurons, and a second stage seeks the best training with varying the number of hidden neurons.

For the process for concentrating omega-3, it was necessary to model two stages of molecular distillation. Two alternatives for modeling ANN were tried: Alternative A (global model) that models the overall process of the two stages as a single process without the intervention of internal current values and Alternative B (staged model), which consists of the development of an ANN model for each stage of molecular distillation, which is simulated under sequential structure modeling.

Both alternatives work with a multilayered network. The neurons in the hidden layer allow a nonlinear mapping of the system. The number of neurons in the input layer is equal to the number of independent variables in the input of each ANN model, and the number of neurons in the output layer corresponds to the number of output variables resulting from each ANN model.
The function of the hidden layer is the hyperbolic tangent sigmoid transfer function (1):

$$
f(x)=\frac{2}{1+e^{-2 \pi}}-1
$$

The results achieved by the global ANN model were confronted with the experimental data reported by Rossi et al. (2011). For this purpose, Relative Error (2) was defined as the difference between the experimental data and the results obtained by the global model ANN and the correlation coefficient (R-value) (3) coefficient between the outputs of the ANN model (relationship between the flow of the distillation of stage 2 and the mass composition of omega-3 in the distillation of stage 2) and targets (experimental data) was used to choose the best alternative. The number of neurons in the hidden layer which are the most appropriate in each model are shown in Table 1.

$$
\begin{aligned}
& \text { Error }=\frac{\left|Y_{\text {exp }}-Y_{A N N}\right|}{Y_{\pi-y}} \\
& R-\text { value }=\sqrt{\frac{\sum_{y}\left(Y_{A N N}-\hat{y}\right)^{2}}{\sum_{y}\left(Y_{\text {exp }}-\hat{y}\right)^{2}}}
\end{aligned}
$$

Where $Y_{\text {exp }}$ is the experimental data; $Y_{A N N}$ is the results obtained by the ANN model $\hat{y}$ is the experimental media value defined as (4).

$$
Y=\frac{1}{\pi} \sum_{1=0}^{\pi} Y_{\text {expi }}
$$

The input data corresponding to temperature \# 1 and $2\left(\mathrm{~T}^{1}\right.$ and $\left.\mathrm{T}^{2}\right)$ and the output data corresponding 


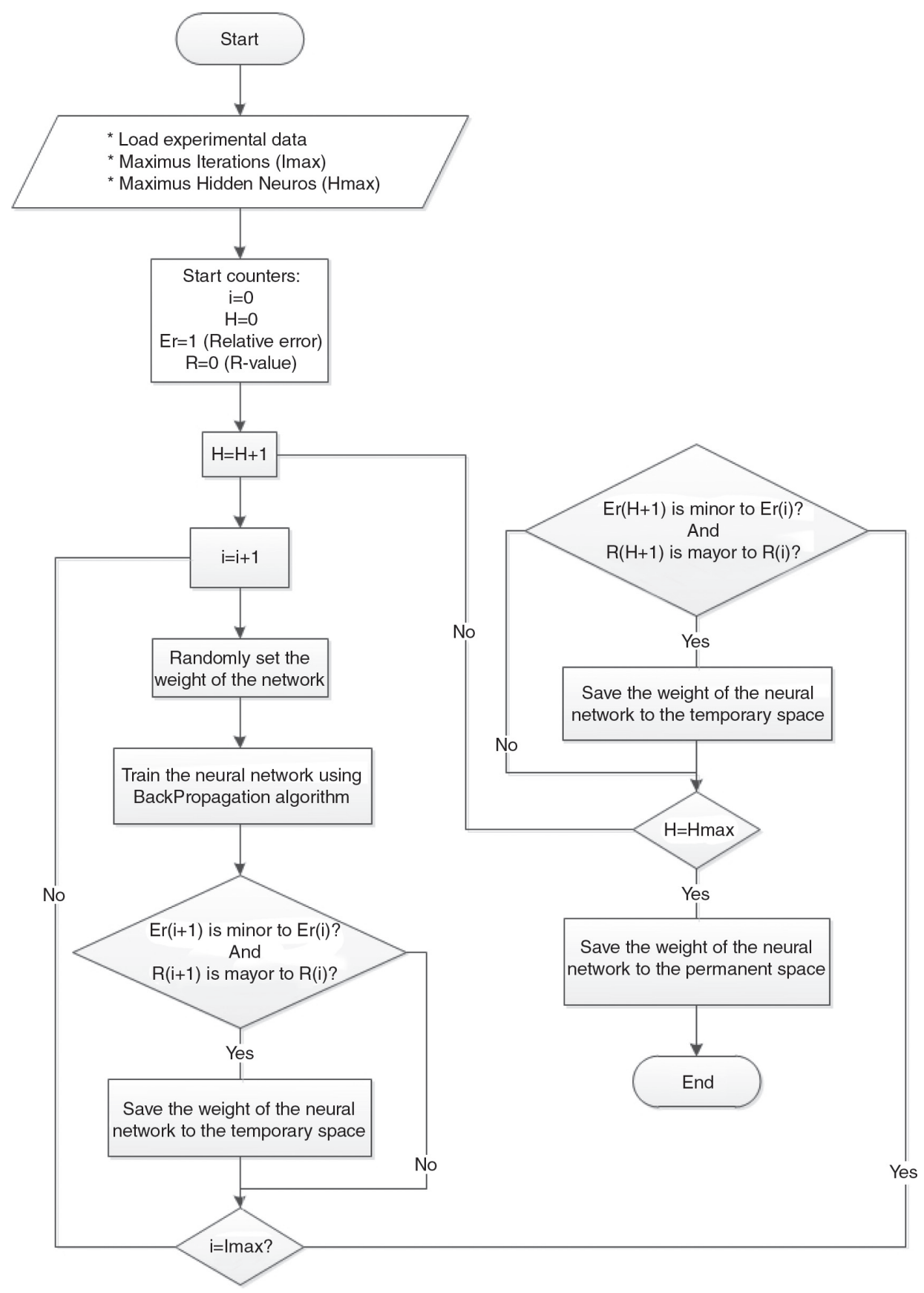

FiguRE 2. Flow sheet of the algorithm used to model the process of the concentration of omega-3 compounds by molecular distillation for obtaining the optimum number of neurons in the hidden layer with the best training.

to the distillation flow and feeding compound ratio $\left(\mathrm{D}^{1 / \mathrm{F}}\right.$ and $\left.\mathrm{D}^{2} / \mathrm{F}\right)$ and mass fractions of the ethyl ester of fatty acids $\left(\mathrm{X}^{1}\right.$ and $\left.\mathrm{X}^{2}\right)$ are presented in Table 2. The experimental data of the molecular distillation experiment were $40 \mathrm{~Pa}$ pressure, $150 \mathrm{rpm}$ rotor speed, $60^{\circ} \mathrm{C}$ feed temperature, and evaporating temperatures between 100 and $120^{\circ} \mathrm{C}$ for the first stage and 120 and $140{ }^{\circ} \mathrm{C}$ for the second stage (Rossi et al., 2011).

\section{RESULTS AND DISCUSSION}

The linear regression between targets and outputs of the global ANN model used to train the network are shown in Figure 3. Between the alternatives proposed for modeling ANN, the Alternative A had a higher correlation coefficient $(\mathrm{R}=0.994)$ and better approximation to the theoretical model 
TABLE 1. Variables and parameters involved in the artificial neural network

\begin{tabular}{|c|c|c|c|}
\hline & \multirow{2}{*}{$\begin{array}{l}\text { Alternative A: } \\
\text { Global model }\end{array}$} & \multicolumn{2}{|c|}{ Alternative B: Individual model } \\
\hline & & Stage I & Stage II \\
\hline \multirow[t]{2}{*}{ Input } & $T^{1} T^{2}$ & $T^{1}$ & $T^{2}$ \\
\hline & & & $\begin{array}{c}X_{P A-E E}^{R^{1}} X_{O A-E E}^{R^{1}} \\
X_{E P A-E E}^{R^{1}} X_{D H A-E E}^{R^{1}}\end{array}$ \\
\hline \multirow[t]{3}{*}{ Output } & $\begin{array}{c}X_{P A-E E}^{D^{1}} X_{O A-E E}^{D^{1}} \\
X_{E P A-E E}^{D^{1}} X_{D H A-E E}^{D^{1}}\end{array}$ & $\begin{array}{c}X_{P A-E E}^{D^{1}} X_{O A-E E}^{D^{1}} \\
X_{E P A-E E}^{D^{1}} X_{D H A-E E}^{D^{1}}\end{array}$ & $\begin{array}{c}X_{P A-E E}^{D^{2}} X_{O A-E E}^{D^{2}} \\
X_{E P A-E E}^{D^{2}} X_{D H A-E E}^{D^{2}}\end{array}$ \\
\hline & $\begin{array}{c}X_{P A-E E}^{D^{2}} X_{O A-E E}^{D^{2}} \\
X_{E P A-E E}^{D^{2}} X_{D H A-E E}^{D^{2}}\end{array}$ & - & - \\
\hline & $D^{1} / F D^{2} / F$ & $D^{1} / F$ & $D^{2} / F$ \\
\hline Number of layers & 3 & 3 & 3 \\
\hline Number of neurons in the hidden layer & 10 & 6 & 10 \\
\hline Hidden layer function & Tansig & Tansig & Tansig \\
\hline
\end{tabular}

Where $D^{j} / F$ : Flow of the distillated stream of the $j$-stage respect to the flow of the feed stream; $T^{k}$ : Temperature of evaporation of the stage $k,\left[{ }^{\circ} \mathrm{C}\right] ; X_{i}^{D j}$ : Mass composition of $i$-compound in the distillated stream of the $j$-stage, $\left[\mathrm{g} \mathrm{g}^{-1}\right]$.

than the Alternative $B(R=0.883)$. Therefore, the model that best represents the process of molecular distillation operation for obtaining a concentrate of omega-3 fatty acids from squid oil is the Alternative A (global model).

Tables 2 and 3 present the percentages of the ratio of the distillation flow of stage 2 to the feeding flow obtained by the global ANN model and the percentages obtained by the ANN model of the omega-3 mass in the distilled phase of stage 2 to the feeding mass also obtained by the global ANN model. An error margin of less than $10 \%$ was observed between the global ANN model and the experimental data.

The relation of $\% \mathrm{D}^{2} / \mathrm{F}$ obtained by the global ANN model, with respect to the temperature of step $2\left(\mathrm{~T}^{2}\right)$ when the stage $1\left(\mathrm{~T}^{1}\right)$ temperature is parametric is shown in Figure 4. It was observed that the flow rate of distillate exhibited an inverse relationship to $\mathrm{T}^{1}$ and a direct relationship to $\mathrm{T}^{2}$.

The behavior of $X^{\mathrm{D} 2} \omega 3$, obtained by the global ANN model, with respect to the temperature of step 2 $\left(\mathrm{T}^{2}\right)$ and parametric in the temperature of stage $1\left(\mathrm{~T}^{1}\right)$

TABLE 2. Experimental data used during the training of the ANN models

\begin{tabular}{|c|c|c|c|c|c|c|c|c|c|c|c|}
\hline \multicolumn{2}{|c|}{ Input data } & \multicolumn{10}{|c|}{ Output responses } \\
\hline$T^{1}$ & $\mathbf{T}^{2}$ & $D^{1} / F$ & $\mathrm{D}^{2} / \mathrm{F}$ & $\mathbf{X}_{\mathrm{EPA-EE}}^{1}$ & $\mathbf{X}_{\text {DHA-EE }}^{1}$ & $\mathbf{X}_{\mathrm{PA}-\mathrm{EE}}^{1}$ & $\mathbf{X}_{\mathrm{OA}-\mathrm{EE}}^{1}$ & $\mathbf{X}_{\mathrm{EPA}-\mathrm{EE}}^{2}$ & $\mathbf{X}_{\text {DHA-EE }}^{2}$ & $\mathbf{X}_{\mathrm{PA}-\mathrm{EE}}^{2}$ & $\mathbf{X}_{\mathrm{OA-EE}}^{2}$ \\
\hline 100 & 120 & 14.3 & 43.1 & 9.3 & 10.8 & 35.2 & 44.7 & 18.3 & 21.6 & 27.1 & 33.0 \\
\hline 100 & 130 & 14.3 & 50.8 & 9.3 & 10.8 & 35.2 & 44.7 & 19.8 & 23.7 & 25.6 & 30.9 \\
\hline 100 & 140 & 14.3 & 51.2 & 9.3 & 10.8 & 35.2 & 44.7 & 21.8 & 26.2 & 23.6 & 28.4 \\
\hline 110 & 120 & 28.4 & 26.3 & 10.5 & 12.2 & 34.3 & 43.0 & 19.7 & 23.3 & 26.0 & 31.0 \\
\hline 110 & 130 & 28.4 & 37.3 & 10.5 & 12.2 & 34.3 & 43.0 & 25.7 & 30.9 & 19.9 & 23.5 \\
\hline 110 & 140 & 28.4 & 42.0 & 10.5 & 12.2 & 34.3 & 43.0 & 23.8 & 28.8 & 21.8 & 25.6 \\
\hline 120 & 120 & 49.5 & 12.5 & 13.4 & 15.7 & 31.7 & 39.2 & 27.4 & 32.9 & 18.7 & 21.0 \\
\hline 120 & 130 & 49.5 & 18.9 & 13.4 & 15.7 & 31.7 & 39.2 & 30.6 & 37.3 & 15.2 & 16.9 \\
\hline 120 & 140 & 49.5 & 21.6 & 13.4 & 15.7 & 31.7 & 39.2 & 30.5 & 37.6 & 15.0 & 16.9 \\
\hline
\end{tabular}

Where $T^{1}$ and $T^{2}$ are the temperature of evaporation of stages 1 and 2 respectively $\left[{ }^{\circ} \mathrm{C}\right] ; D^{1} / F$ and $D^{2} / F$ are the percentage of distillated flow of stage 1 and 2 respectively and feeding flow ratio; $X_{i}^{D 1}$ and $X_{i}^{D 2}$ are the percentages of omega-3 mass faction in the distillated phase of 1 and 2 respectively [ $\mathrm{g} \mathrm{g}^{-1} \%$, where $i$-compound are the ethyl ester of EPA (EPA-EE), ethyl ester of DHA (DHA-EE), ethyl ester of palmitic acid (PA-EE) and ethyl ester of oleic acid (OA-EE). 


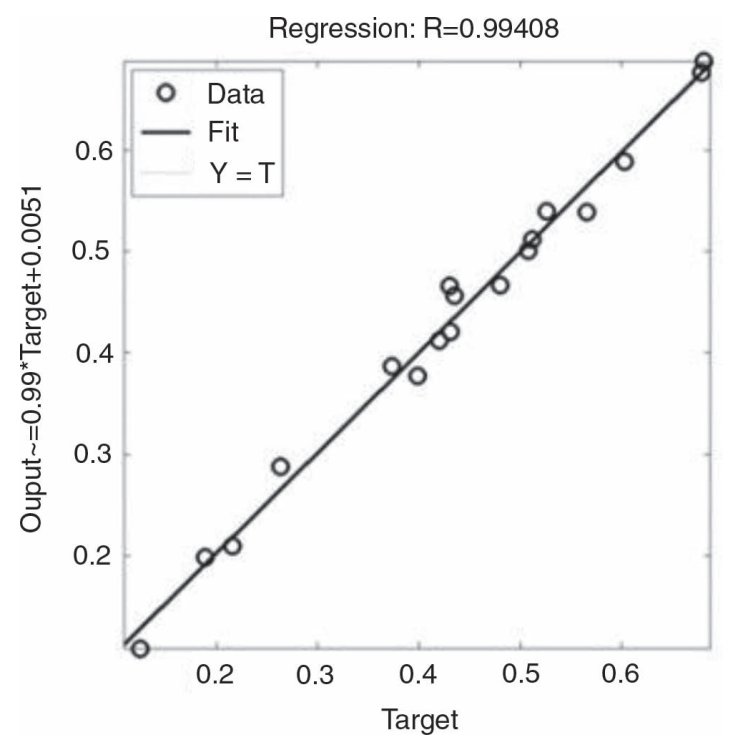

FIGURE 3. Lineal regression between the targets and outputs of the global model.

Abbreviation: $\mathrm{Y}=\mathrm{T}$ is an ideal fit; Data is the experimental data; Fit is the linear regression between ANN model results and experimental data; Output is the ANN model results (relationship between the flow of the distillated phase of stage 2 and the mass composition of omega- 3 in the distillated phase of stage 2); Target is the experimental data.

is presented in Figure 5. It was observed that the mass composition of omega- 3 in the distillate stream showed a direct relationship to the temperatures $T^{1}$ and $\mathrm{T}^{2}$. The Operative variables considered in this study were $\mathrm{T}^{1}$ and $\mathrm{T}^{2} . \mathrm{T}^{1}$ presented a compromise situation between the purity of omega-3 and quantity of product. Instead, $\mathrm{T}^{2}$ showed an increasing trend of

TABle 3. Comparison of flow rate between global model and experimental results

\begin{tabular}{|c|c|c|c|c|}
\hline $\left.\mathbf{T}^{1}{ }^{\circ} \mathbf{C}\right]$ & $\left.\mathrm{T}^{2}{ }^{\circ}{ }^{\circ}\right]^{\mathrm{a}}$ & $\operatorname{Exp}_{\% \mathbf{D}^{2} / \mathbf{F}^{\mathrm{a}, \mathrm{b}}}$ & $\begin{array}{c}\mathbf{A N N} \\
\% \mathbf{D}^{2} / \mathbf{F}^{\mathrm{a}}\end{array}$ & Error \% \\
\hline 100 & 120 & 43.1 & 42.0 & 2.6 \\
\hline 100 & 130 & 50.8 & 50.1 & 1.4 \\
\hline 100 & 140 & 51.2 & 51.2 & 0 \\
\hline 110 & 120 & 26.3 & 28.8 & 8.7 \\
\hline 110 & 130 & 37.3 & 38.7 & 3.6 \\
\hline 110 & 140 & 42.0 & 41.2 & 1.9 \\
\hline 120 & 120 & 12.5 & 10.9 & 14.7 \\
\hline 120 & 130 & 18.9 & 19.8 & 4.5 \\
\hline 120 & 140 & 21.6 & 21.0 & 2.9 \\
\hline
\end{tabular}

${ }^{a}$ Where $T^{1}$ is the temperature $\left({ }^{\circ} \mathrm{C}\right)$ of stage $1, T^{2}$ is the temperature $\left({ }^{\circ} \mathrm{C}\right)$ of stage 2, Exp $\mathrm{D}^{2} / \mathrm{F}$ is the percentage of distillated flow of stage 2 and feeding flow ratio obtained experimentally. ANN $\mathrm{D}^{2} / \mathrm{F}$ is the ANN model result.

${ }^{\mathrm{b}} \operatorname{Exp~D}^{2} / \mathrm{F}$ (Rossi et al., 2011).

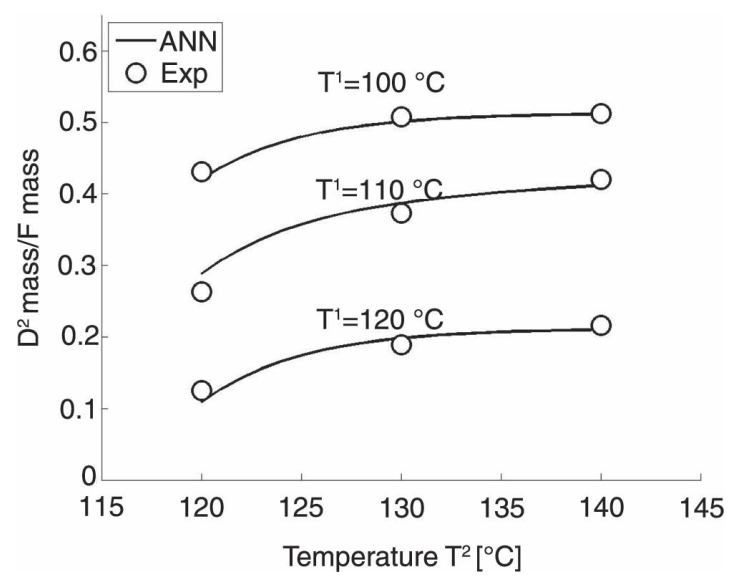

FIGURE 4. Relation between the distilled flow of stage 2 and the feeding flow at different temperatures (T2) in stage 2. $\mathrm{T}^{1}$ is the temperature $\left({ }^{\circ} \mathrm{C}\right)$ of stage $1, \mathrm{~T}^{2}$ is the temperature of stage 2, ANN is the data obtained by the ANN model, and Exp is the experimental data.

$X^{\mathrm{D} 2} \omega 3 . \mathrm{T}^{2}$ was restricted to $140^{\circ} \mathrm{C}$ due to the presence of thermo labile compounds such as EPA and DHA omega-3 fatty acids that generate undesired changes in the final product (Liang and Hwang, 2000).

Theoretical concepts based on phenomenological laws were very important for the construction of the ANN structure. Numerous studies (Pramparo et al., 2008; Liñan et al., 2012; Oterhals et al., 2010) showed that the molecular distillation phenomenon presents a constant and uniform behavior for all operative variables, where there is no oscillating or erratic behavior. This kind of model correctly describes the nonlinear behavior of the molecular distillation phenomenon but it has the disadvantage of requiring experimental data for validation

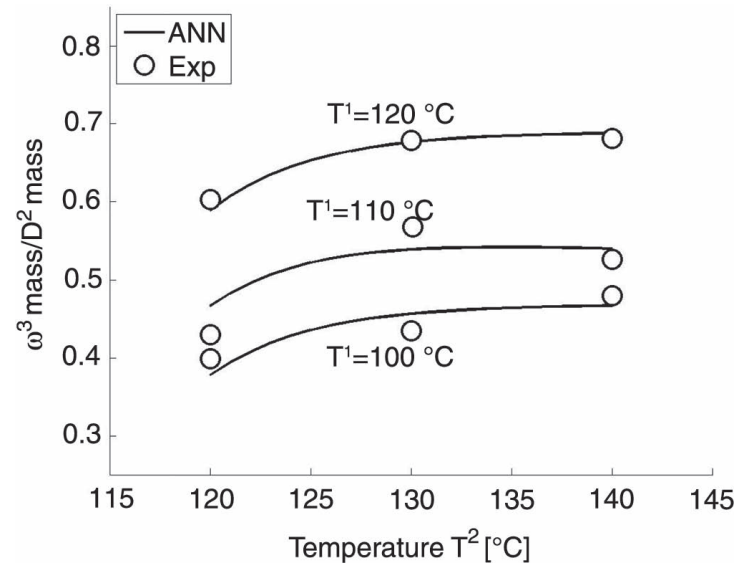

FIGURE 5. Mass fraction of omega-3 in the distilled of stage 2 at different temperatures (T2) in the stage 2.

$\mathrm{T}^{1}$ is the temperature $\left({ }^{\circ} \mathrm{C}\right)$ of the stage $1, \mathrm{~T}^{2}$ is the temperature of the stage 2, ANN is the data obtained by ANN model, and Exp is the experimental data. 
TABLE 4. Comparison of mass composition of omega-3 between the global model and experimental results

\begin{tabular}{|c|c|c|c|c|}
\hline $\mathrm{T}^{1}\left[{ }^{\circ} \mathrm{C}\right]$ & $\mathrm{T}^{2}\left[{ }^{\circ} \mathbf{C}\right]^{\mathrm{a}}$ & $\begin{array}{l}\operatorname{Exp}_{X^{D 2}}^{D^{2}} \omega 3 \\
{\left[g^{-1} g^{-1}\right]^{\text {a, b }}}\end{array}$ & 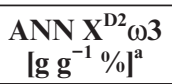 & Error \\
\hline 100 & 120 & 39.9 & 37.8 & 5.3 \\
\hline 100 & 130 & 43.5 & 45.6 & 4.8 \\
\hline 100 & 140 & 48.0 & 46.8 & 2.5 \\
\hline 110 & 120 & 43.0 & 46.6 & 8.4 \\
\hline 110 & 130 & 56.6 & 53.9 & 4.8 \\
\hline 110 & 140 & 52.6 & 53.9 & 2.5 \\
\hline 120 & 120 & 60.3 & 58.9 & 2.3 \\
\hline 120 & 130 & 67.9 & 67.6 & 0.4 \\
\hline 120 & 140 & 68.1 & 68.8 & 1.0 \\
\hline
\end{tabular}

${ }^{\text {a }}$ Where: $\mathrm{T}^{1}$ is the temperature $\left({ }^{\circ} \mathrm{C}\right)$ of stage $1, \mathrm{~T}^{2}$ is the temperature $\left({ }^{\circ} \mathrm{C}\right)$ of stage 2 , Exp $\mathrm{X}^{\mathrm{D} 2} \mathrm{\omega} 3$ is the percentage of omega- 3 mass faction in the distillated phase of stage 2 obtained experimentally. ANN X ${ }^{\mathrm{D} 2} \omega 3$ is the ANN model result.

${ }^{\mathrm{b}} \operatorname{Exp~} \mathrm{X}^{\mathrm{D} 2} \omega 3$ (Rossi et al., 2011).

and verification, only. The rigorous phenomenological modeling of molecular distillation provides significant information regarding the performance of the operation and the physical phenomena that take place (Liñan et al., 2012; Hu et al., 2013). The phenomenological modelling of the molecular distillation contributes with important information about the performance of the equipment operation and the physical phenomenon that occurs during the process. This kind of modelling involves a great mathematical complexity; and also, the phenomenological modelling can estimate the influence of every operative variable and how those variables affect the yield of the process (Lutisan et al., 2002).

Rigorous phenomenological models can predict the influence that each of the operative variables has and describe the phenomenon that takes place on the inside of the equipment or how the variables affect the performance of the process (Liñan et al., 2012; Hu et al., 2013). However, this kind of model cannot predict the behavior of certain functional variables of the equipment, such as the shake mechanism (roller-wiper), without considerably increasing the mathematical complexity. On the other hand, an ANN model does not give any kind of information about the particular phenomenon, but, with an appropriate training of the network, it can predict the effects of variables, such as the speed of the shake mechanism (Shao et al., 2007; Li et al., 2011). In addition, the artificial neural network constitutes a useful tool for modelling the process of molecular distillation with great precision but it needs a great amount the experimental data and does not give information about a determined effect (Shao et al., 2007; Haykin, 2009; Lima et al., 2011).
The use of methods that combine both models for molecular distillation could be an interesting alternative to take advantages from both models.

There are other alternatives to phenomenological models like surface response, fuzzy logic, and genetic algorism, among others, that have a great adaptation capability to the phenomena even for those that are nonlinear, do not require previous knowledge of the phenomena; and do not need great mathematical complexity. ANN also has these advantages (Shao et al., 2007; Lima et al., 2011; Li et al., 2011).

\section{CONCLUSIONS}

Modeling with artificial neural networks allows for the prediction of the behavior of a molecular distillation process in two stages to concentrate the ethyl esters of omega- 3 fatty acids. In addition, the knowledge about the phenomenological concept obtained from the modeling with artificial neural networks were useful for selecting different parameters necessary for building the ANN model.

\section{ACKNOWLEDGEMENTS}

The authors wish to thank CONICET (Consejo Nacional de Investigaciones Científicas y Técnicas) for supporting this research and the Secretaría de Ciencia, Tecnología e Innovación, Gobierno de la Provincia de Chubut, for their contribution and interest in this subject.

\section{REFERENCES}

Bulsari, A. 1995. Neural Networks for Chemical Engineers. Elsevier Science Inc, New York.

Cvengros J, Lutisan J, Micov M. 2000. Feed temperature influence on the efficiency of a molecular evaporator. Chem. Eng. J. 78, 61-7. http://dx.doi.org/10.1016/ S1385-8947(99)00159-X.

Ferron J, Bandarkar M. 1991. Simulation of Rarefied Vapor Flows. IND ENG CHEM RES. 30, 998-1007. http:// dx.doi.org/10.1021/ie00053a023.

Haykin S. 2009. Neural Networks and Learning Machines (3rd edition). Pearson Education Inc, New Jersey.

$\mathrm{Hu}$ H, Huang J, Wu S, Yu P. 2013. Simulation of vapor flows in short path distillation. Comput Chem Eng. 49, 127-135. http://dx.doi.org/10.1016/j.compchemeng.2012.10.002.

$\mathrm{Li} \mathrm{H}, \mathrm{Hu} \mathrm{C}, \mathrm{Li}$ Y. 2011. The application of natural vitamin E purification in molecular distillation based on GA-BP. Electronics, Communications and Control (ICECC). 1, 2339-2342.

Liang J, Hwang L. 2000. Fractionation of squid visceral oil ethyl esters by short-path distillation. J. Am. Chem. Soc. 77, 773-777.

Lima N, Liñan L, Manenti F, Maciel Filho R, Wolf Maciel M, Embiruçu M, Medina L. 2011. Fuzzy cognitive approach of a molecular distillation process. Chem. Eng. Res. Des. 89, 471-479. http://dx.doi.org/10.1016/j.cherd.2010.08.010.

Liñan Z, Lima N, Manenti F, Wolf Maciel M, Maciel Filho R, Medina L. 2012 Experimental campaign, modeling, and sensitivity analysis for the molecular distillation of petroleum residues 673.1K. Chem. Eng. Res Des. 90, 243-258. http://dx.doi.org/10.1016/j.cherd.2011.07.001. 
Lutisan J, Cvengros J, Micov M. 2002. Heat and mass transfer in the evaporating film of a molecular evaporator. Chem. Eng. J. 85, 225-234. http://dx.doi.org/10.1016/ S1385-8947(01)00165-6.

Mathworks, 2013. Description of the neural network toolbox: ToolboxNN v8. 1. Design and simulate neural networks. http://www.mathworks.com/products/neuralnet/.

Oterhals A, Kvamme B, Berntssen M. 2010. Modeling of a short-path distillation process to remove persistent organic pollutants in fish oil based on process parameters and quantitative structure properties relationships. Chemosphere. 80, 83-92. http://dx.doi.org/10.1016/j. chemosphere.2010.04.016

Posada L, Shi j, Kakuda Y, Xue S. 2007. Extraction of Tocotrienols from Fatty Acid Distillates Using Molecular Distillation. Sep. Purif. Technol. 57, 220-229. http://dx.doi. org/10.1016/j.seppur.2007.04.016.

Pramparo M, Martinello M, Leone I. 2008. Simulation of Deacidification Process by Molecular Distillation of Deodorizer Distillate. Lat. Am. Appl. Res. 38, 299-304.

Rossi PC, Pramparo M, Gaich M, Grosso R, Nepote V. 2011. Optimization of molecular distillation to concentrate the ethyl ester of eicosapentaenoic (20:5 103$)$ and docosahexaenoic acids (22:603) using simplified phenomenological modeling. J. Sci. Food Agr. 91, 1452-1458. http://dx.doi. org/10.1002/jsfa.4332.

Setyawan H, Hambali E, Suryani A, Setyaningsih D. 2011. Separation of Tocopherol from Crude Palm Oil Biodiesel. J. Basic Appl. Sci. 1, 1169-1172.

Shao P, Jiang S, Ying Y. 2007. Optimization of molecular distillation for recovery of tocopherol from rapeseed oil deodorizer distillate using response surface and artificial neural network models. Food Bioprod. Process. 85, 85-92. http:// dx.doi.org/10.1205/fbp06048.

Swanson D, Block R, Mousa S. 2012. Omega-3 Fatty Acids EPA and DHA: Health Benefits Throughout Life. Adv. Nutr. Res. (1-7). http://dx.doi.org/10.3945/an.111.000893.

Tovar L, Wolf Maciel M, Winter A, Batistella C, Filho R, Medina L. 2012. Reliability-Based Optimization using Surface Response Methodology to Split Heavy Petroleum Fractions by Centrifugal Molecular Distillation Process. Separ. Sci. Technol. 47.

Vansant E. 1994. Separation technology (Process Technology Proceeding). Elsevier, Amsterdam. 